\title{
Eosinophilic Heart Disease: A Case Report and Review of Literature
}

\author{
Ghulam Akbar*, Fnu Vikram, Ronald Freudenberger and Matthew Martinez \\ Department of Cardiovascular Medicine, Lehigh Valley Hospital Cedar Crest, USA
}

Submission: March 08, 2017; Published: March 30, 2017

*Corresponding author: Ghulam Akbar, Department of Cardiovascular Medicine, Lehigh Valley Health Network, 1250 S Cedar Crest Blvd, Lehigh Valley Hospital, Allentown, PA 18103, Email: Ghulam.akbar@lvhn.org

\begin{abstract}
Hypereosinophilic syndrome is a rare condition and present with nonspecific symptoms. Literature is limited. The involvement of myocardium has some peculiar features. Use of different diagnostic techniques such as echocardiography and MRI can help make the diagnosis of hypereosinophilic syndrome. We are presenting a case with review of the topic.

Keywords: Hypereosinophilic syndrome; Hypereosinophilic heart disease; Eosinophilic myocarditis; Apical hypertrophy; Apical thrombosis

Abbreviations: HES: Hyper Eosinophilic Syndrome; EHD: Eosinophilic Heart Disease; HE: Hyper Eosinophilia
\end{abstract}

\section{Introduction}

Hypereosinophilic syndrome (HES) is a multisystem disorder diagnosed by the presence of hypereosinophilia (HE) defined as an absolute eosinophil count (AEC) $>1.5 \times 109 / \mathrm{L}$ (or $>1500$ cells/microL) and multi organ involvement attributable to HE. Myocardial dysfunction is a frequent finding and is a major cause of morbidity and mortality in HES. The diagnosis of hypereosinophilic heart disease (EHD) is made in the setting of hypereosinophilia and characteristic clinical features and imaging findings of damage to the heart. We describe those clinical features in this case of HES with HHD with review of literature.

\section{Case Report}

A 63 year old male with no known past medical history was transferred to our hospital for hypotension, abnormal EKG and elevated troponin. The patient described nonspecific symptoms of cough, runny nose, malaise, muscle aches, nausea, diarrhea and low grade fever for 2-3 weeks. He also noted a skin rash which had resolved at the time of admission. He denied air travel outside the United States, no prior known malignancies or inflammatory diseases such as vasculitis or autoimmune diseases. He has no history of diabetes mellitus, hypertension or hyperlipidemia but is an active smoker. His examination revealed diminished lung sounds bilaterally, normal heart sounds with a soft $1 / 6$ intensity holosystolic murmur without marked radiation of the murmur. There was mild lower extremity edema present. His electrocardiogram showed sinus rhythm with diffuse T-wave inversions. He had a contrast enhanced CT of his chest abdomen and pelvis which revealed no pulmonary embolism or dissection, marked lymphadenopathy and small pleural effusions only. His pertinent laboratory data revealed hyponatremia, normal creatinine and an elevated troponin I value of 2.89. He was found to have an elevated white blood cell count of 15000 , hemoglobin 9 gram/dl and platelet count of 40,000. His eosinophil count was 4800 (UNITS). A transthoracic echocardiogram revealed hyperdynamic left ventricular (LV) systolic function and apical thickening concerning for an LV thrombus (Figure 1a \& 1b). An MRI of the heart confirmed the diagnosis of apical thrombus along with fibrotic material seen in both LV and RV apex (Figure $2 \mathrm{a} \& 2 \mathrm{~b}$ ). In the presence of hypereosinophilia and the imaging findings a diagnosis of HES was made. He was initiated on anticoagulation.

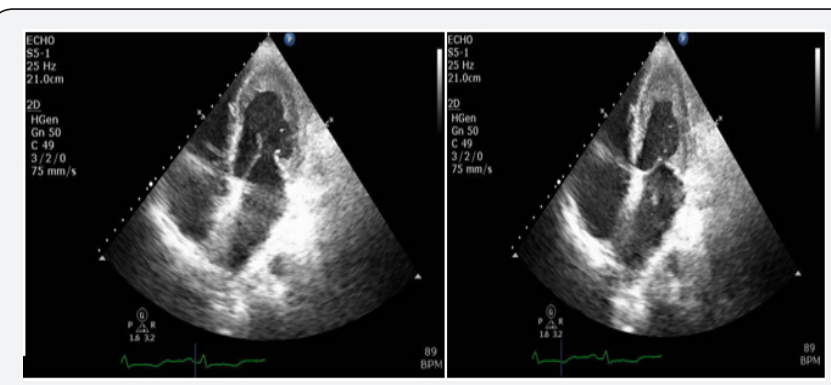

Figure 1a \& 1b: Echocardiographic image illustrating apical thrombus without apical myocardial thinning. 


\section{Journal of Cardiology \& Cardiovascular Therapy}

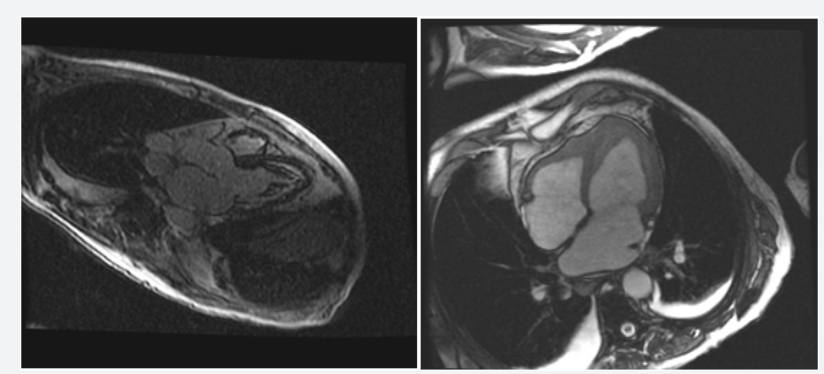

Figure 2a \& 2b: (a) Cardiac MRI with Steady State Free Precision imaging (SSFP) illustrating apical thrombus in the LV and RV. (b) Late gadolinium enhancement image showing a clear LV thrombus without underlying myocardial infarction.

\section{Discussion}

HES are a heterogeneous group of disorders. Typically symptoms are very nonspecific as in our case. A rash, GI disturbances, cough and dyspnea are the common symptoms. Myocardial involvement in HES was first described in 1936 by Wilhelm Loffler who reported a 'fibroplastic parietal endocarditis with blood eosinophilia' [1]. Prevalence of EHD in HES is up to $50 \%[2,3]$. Myocardial dysfunction is a major cause of morbidity and mortality. Hence timely diagnosis and treatment may improve patient outcome $[3,4]$.

Pathophysiology of EHD includes three overlapping stages: 1) an acute necrosis, 2) thrombosis and 3) fibrosis. Acute necrosis is felt to be caused by eosinophilic infiltration and activation with release of inflammatory mediators and toxic proteins. In second stage, at the site of damaged and exposed endocardium, platelets bind with von Willebrand factor and collagen to form a thrombus. Thrombus formation can occur in both ventricles typically at the apices. However, it can be located at the valvular, subvalvular or in the outflow tracts. Systemic thromboembolism remains a major concern of morbidity and mortality in up to $25 \%$ of patients. In the final stage, thrombosed endocardium is replaced by fibrosis resulting in scarring, valvular regurgitation and restrictive cardiomyopathy. The clinical presentation of EHD is variable and may range from an asymptomatic myocardial involvement to heart failure syndrome, conduction abnormality, fatal arrhythmia, sudden cardiac death or an acute coronary like syndrome. Arrhythmias are due to fibrosis of the conduction system or myocardial scarring. Acute coronary syndrome is rare but can occur due to embolic coronary artery occlusion [5-7].

It is important to note that EHD can be seen in any cause of eosinophilia or hypereosinophilia such as drugs and hypersensitivity reactions, parasitic or protozoal infections, malignancies or idiopathic hypereosinophilic syndromes [8].

Medications are frequently implicated as an etiology of hypereosinophilia. A wide spectrum of drugs can lead to HE and include antimicrobials, anti-inflammatory, antipsychotics, anticonvulsants, diuretics, inotropes and ACE inhibitors $[9,10]$. Eosinophilic myocarditis has also been described with hypereosinophilic vasculitides such as eosinophilic granulomatosis with polyangiitis (EGPA). HE can be reactive or part of a proliferative clone in solid and hematological malignancies such as lung, GIT, urogential tumors, T and B cell lymphomas, acute and chronic myeloid leukemia and myeloproliferative disorders

\section{Diagnosis}

Endomyocardial biopsy is the reference standard test for the definite diagnosis of EHD. However, biopsy is often not performed due to its invasive nature, leaving the diagnosis made based on the appropriate clinical data and imaging modalities. It is important to note that a biopsy may be negative in cases with focal cardiac involvement. Eosinophilia is present in the majority of the patients with EHD. Electrocardiographic changes are common but nonspecific and may include criteria for left ventricular hypertrophy, arrhythmias, first degree AV block. T-wave inversions are most frequently found as seen in our case. T-Wave inversions are likely manifestations of subendocardial injury and fibrosis [11]. Echocardiography plays a vital role in suspecting and identifying EHD. Echocardiographic findings may vary depending on stage of presentation and degree of myocardial involvement. Characteristic echocardiographic features of EHD include endomyocardial thickening in up to $68 \%$ of the cases, apical obliteration/thickening due to thrombus formation and restricted posterior mitral leaflet. Other conditions such as LV noncompaction, apical hypertrophic cardiomyopathy and isolated LV apical thrombus may mimic the echocardiographic images of EHD. Different imaging techniques such as use of echo contrast agents, transesophageal echocardiography with three dimension windows and magnetic resonance imaging (MRI) can make the differentiation among these conditions [11-13]. In fulminant cases of myocarditis, a non-dilated, thickened, and hypocontractile left ventricle (LV) is usually observed. Myocardial fibrosis can result in restrictive cardiomyopathy in later stages which can be assessed with Doppler data. Cardiac MRI has higher sensitivity and specificity than any other imaging modalities and contrast-enhanced Cardiac MRI can identify inflammation and fibrosis in its early stages even when echocardiography findings may be normal [14-17]. Interestingly, the severity of eosinophilia was directly related with the severity of MRI findings in few case reports [17]. In our patient, Cardiac MRI showed circumferential apical endocardial thickening/ fibrosis after gadolinium contrast administration and LV apical thrombus, which is pathognomonic of EHD. Cardiac computed tomography (CT) may be used to evaluate the coronary artery disease as a potential cause of apical thrombus if concomitant wall motion or severe systolic dysfunction is present [18]. Coronary angiography has little role and is only used to rule out coronary artery disease.

Treatment of EM involves both pharmacologic and nonpharmacologic therapies. Pharmacologic therapies include guideline driven therapies specific to cardiac presentation, anticoagulation and steroids. In addition it is important to find the etiology of hypereosinophila and treat it accordingly. In 
suspected cases of drug hypersensitivities, offending drug needs to be discontinued and chemotherapeutic agent is used for solid and hematologic malignancies. Patients with Churg Strauss syndrome are treated with steroids with or without steroid sparing agents. Recently non FDA approved therapeutic agents targeting IL-5 receptors as Benralizumab have shown promising reduction in blood and tissue eosinophilia [19].

\section{References}

1. Valent P, Klion AD, Horny HP, Roufosse F, Gotlib J, et al. (2012) Contemporary consensus proposal on criteria and classification of eosinophilic disorders and related syndromes. J Allergy Clin Immunol 130(3): 607-612.

2. Spry CJ, Take M, Tai PC (1985) Eosinophilic disorders affecting the myocardium and endocardium: a review. Heart Vessels Suppl 1: 240242.

3. Podjasek JC, Butterfield JH (2013) Mortality in hypereosinophilic syndrome: 19 years of experience at Mayo Clinic with a review of the literature. Leuk Res 37(4): 392-395.

4. Lefebvre C, Bletry O, Degoulet P, Guillevin L, Bentata-Pessayre M, et al. (1989) Prognostic factors of hypereosinophilic syndrome. Study of 40 cases. Ann Med Interne (Paris) 140(4): 253-257.

5. Mankad R, Bonnichsen C, Mankad S (2016) Hypereosinophilic syndrome: cardiac diagnosis and management. Heart 102(2): 100-106.

6. Al Ali AM, Straatman LP, Allard MF, Ignaszewski AP (2006) Eosinophilic myocarditis: case series and review of literature. Can J Cardiol 22(14): 1233-1237.

7. Assa'ad AH, Spicer RL, Nelson DP, Zimmermann N, Rothenberg ME (2000) Hypereosinophilic syndromes. Chem Immunol 76: 208-229.

8. Maisch B, Pankuweit S (2012) Current treatment options in (peri) myocarditis and inflammatory cardiomyopathy. Herz 37(6): 644-656.

9. Burke AP, Saenger J, Mullick F, Virmani R (1991) Hypersensitivity myocarditis. Arch Pathol Lab Med 115(8): 764-769.
10. Akuthota P, Weller PF (2015) Spectrum of eosinophilic end-organ manifestations. Immunol Allergy Clin North Am 35(3): 403-411.

11. Parillo JE, Borer JS, Henry WL, Wolff SM, Fauci AS (1979) The cardiovascular manifestations of the hypereosinophilic syndrome. Prospective study of 26 patients, with review of the literature. Am J Med 67(4): 572-582.

12. Shah R, Ananthasubramaniam K (2006) Evaluation of cardiac involvement in hypereosinophilic syndrome: complementary roles of transthoracic, transesophageal, and contrast echocardiography. Echocardiography 23(8): 689-691.

13. Kim NK, Kim CY,KimJH,Jang SY,Bae MH, etal. (2015) Ahypereosinophilic syndrome with cardiac involvement from thrombotic stage to fibrotic stage. J Cardiovasc Ultrasound 23(2): 100-102.

14. Pillar N, Halkin A, Aviram G (2012) Hypereosinophilic syndrome with cardiac involvement: early diagnosis by cardiac magnetic resonance imaging. Can J Cardiol 28(4): 515.e11-3.

15. Porto AG, McAlindon E, Hamilton M, Manghat N, Bucciarelli-Ducci C (2013) Diagnosing cardiac involvement in the hypereosinophilic syndrome by cardiac magnetic resonance. Am J Cardiol 112(1): 135136.

16. Simonnet B, Jacquier A, Salaun E, Hubert S, Habib G (2015) Cardiac involvement in hypereosinophilic syndrome: role of multimodality imaging. Eur Heart J Cardiovasc Imaging 16(2): 228.

17. Miszalski-Jamka T, Szczeklik W, Karwat K, Sokołowska B, Gąsior J, et al. (2015) MRI-based evidence for myocardial involvement in women with hypereosinophilic syndrome. Magn Reson Med Sci 14(2): 107114 .

18. Chen CH, Tsai IC, Jan SL, Tsai WL, Chen CC (2011) MDCT evaluation of cardiac involvement in hypereosinophilic syndrome: differentiating mural thrombus, infarcted, and noninfarcted myocardium by delayedphase scanning. Tex Heart Inst J 38(2): 166-169.

19. Legrand F, Klion AD (2015) Biologic therapies targeting eosinophils: current status and future prospects. J Allergy Clin Immunol Pract 3(2): 167-174.

\section{Your next submission with Juniper Publishers will reach you the below assets}

- Quality Editorial service

- Swift Peer Review

- Reprints availability

- E-prints Service

- Manuscript Podcast for convenient understanding

- Global attainment for your research

- Manuscript accessibility in different formats

( Pdf, E-pub, Full Text, Audio)

- Unceasing customer service

Track the below URL for one-step submission https://juniperpublishers.com/online-submission.php 